University of Nebraska - Lincoln

DigitalCommons@University of Nebraska - Lincoln

1983

\title{
In Situ Studies of Velocity in Fractured Crystalline Rocks
}

Daniel Moos

Stanford University

Mark D. Zoback

U.S. Geological Survey, zoback@stanford.edu

Follow this and additional works at: https://digitalcommons.unl.edu/usgsstaffpub

Part of the Earth Sciences Commons

Moos, Daniel and Zoback, Mark D., "In Situ Studies of Velocity in Fractured Crystalline Rocks" (1983).

USGS Staff -- Published Research. 457.

https://digitalcommons.unl.edu/usgsstaffpub/457

This Article is brought to you for free and open access by the US Geological Survey at DigitalCommons@University of Nebraska - Lincoln. It has been accepted for inclusion in USGS Staff -- Published Research by an authorized administrator of DigitalCommons@University of Nebraska - Lincoln. 


\title{
In Situ Studies of Velocity in Fractured Crystalline Rocks
}

\author{
DANIEL MoOS \\ U.S. Geological Survey, Menlo Park, California 94025 \\ Department of Geophysics, Stanford University, Stanford, California, 94305
}

MARK D. ZOBACK

U.S. Geological Survey, Menlo Park, California, 94025

\begin{abstract}
A study of the effects of macroscopic fractures on $P$ and $S$ wave velocities has been conducted in four wells drilled in granitic rock to depths between 0.6 and $1.2 \mathrm{~km}$. The effect of macroscopic fractures is to decrease both $V_{p}$ and $V_{s}$ and increase $V_{p} / V_{s}$. In wells with a relatively low density of macroscopic fractures, the in situ velocity is similar to that of saturated core samples under confining pressure in the laboratory, and there is a clear correlation between zones with macroscopic fractures and anomalously low velocities. In wells with numerous macroscopic fractures, the in situ velocity is lower than that of intact samples under pressure, and there is a correlation between the rate at which in situ velocity increases with depth and the rate at which the velocity of laboratory samples increases with pressure. Differences in in situ $P$ wave velocity between wells cannot be explained solely by differences in the degree of macroscopic fracturing, thus emphasizing the importance of composition and microcracks on velocity. In one highly fractured well the in situ $P$ wave velocity is essentially the same for frequencies ranging from $10 \mathrm{~Hz}$ to $20 \mathrm{kHz}$; this suggests that the macrofractures affect velocity similarly over a broad frequency range. Chemical alteration of rock adjacent to macroscopic fractures appears to play an important role in reducing in situ velocities. Synthetic reflection seismograms generated from the velocity logs suggest that fracture zones are one possible source of deep-crustal reflectors observed on seismic reflection profiles.
\end{abstract}

\section{INTRODUCTION}

The manner in which microcracks affect the velocity of crystalline rock is well known from laboratory measurements. Birch $[1960,1961]$ showed that in dry crystalline rock, increased confining pressure causes a marked increase in compressional velocity due to the closure of microcracks. Nur and Simmons [1969] later showed that in saturated granitic rock the seismic velocity is markedly higher than in dry rocks and the degree to which confining pressure increases velocity is somewhat diminished.

Although it is well known that the presence of macroscopic fractures in an otherwise homogeneous rock can profoundly affect its seismic velocity, few attempts have been made to systematically relate fracture occurrence and seismic velocities in situ. There are two primary reasons for understanding the relationship between seismic velocity and fractures in the crust. Interpretation of geologic units from seismic velocities depends critically on the degree to which fractures affect velocity. Furthermore, because fractures in the crust are of interest for a variety of reasons, seismic velocity can be used as a tool for the study of those fractures.

Comparisons of field data with laboratory measurements demonstrate the importance of understanding the role of in situ fractures in controlling seismic velocity. Simmons and Nur [1968] measured the $P$ wave velocity of granites in a 3-km-deep hole in the Wind River Range of Wyoming and a 3.8-km-deep hole near Troy, Alabama. They found that in situ velocities were uniformly higher than laboratory measurements on dry samples and increased more slowly with pressure. They attributed this difference to the presence of water in the microcracks in situ. In a similar case, Wang and Simmons [1978] found that in situ velocities for gabbroic rock at 5.3-km depth in the Michigan Basin are

This paper is not subject to U.S. copyright. Published in 1983 by the American Geophysical Union.

Paper number 2B1807. equal to or slightly higher than the velocity of saturated laboratory samples at the appropriate pressure. This discrepancy was attributed to the introduction of stress relief microcracks when the core was removed.

The results are much different when numerous macroscopic fractures are present in situ. Stierman and Kovach [1979] observed little systematic increase of velocity with depth in a 700$\mathrm{m}$-deep well drilled in highly fractured quartz diorite $1.2 \mathrm{~km}$ from the San Andreas fault. Furthermore, a sample from the well had a measured $P$ wave velocity of more than $6 \mathrm{~km} / \mathrm{s}$ in the laboratory, while in situ $P$ wave velocities were less than $4 \mathrm{~km} / \mathrm{s}$. This marked difference was attributed to the numerous macroscopic fractures in the well which were not present in the laboratory specimen. Keys [1979] reported lower sonic compressional velocities associated with fracture zones in the Lac du Bonnet batholith in central Canada at depths up to $350 \mathrm{~m}$. In another study, Sjogren et al. [1979] showed that in very shallow $(<25 \mathrm{~m})$ boreholes, macroscopic fractures reduced in situ compressional wave velocity and that in igneous and metamorphic rocks there was a good correlation between compressional wave velocities and the number of macroscopic fractures.

In order to understand the factors controlling seismic wave velocities in fractured rock we examine here the relationship between macroscopic fracture (macrofracture) density and $P$ and $S$ wave velocities in four wells drilled in fractured granitic rocks. By studying in detail the effect of isolated fractures and fracture zones on seismic velocity we have attempted to understand the mechanisms by which fractures affect velocity in situ. By comparing in situ velocities with measurements made on laboratory samples we have attempted to determine the conditions under which the change of ultrasonic velocity of laboratory samples with pressure adequately explains the change in sonic velocity with depth. Finally, by applying a few simple modeling techniques we examine the conditions under which subsurface fracture zones might be detected by conventional seismic reflection profiling. 


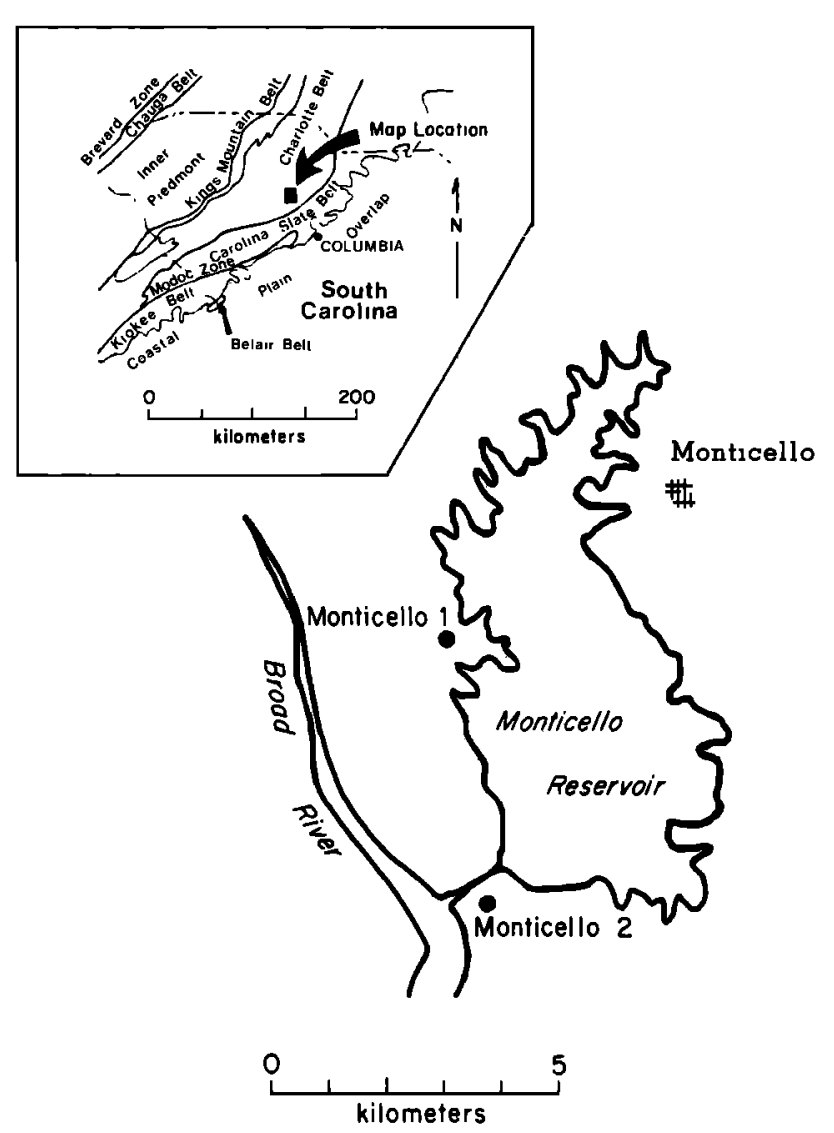

Fig. 1. Map showing the location of the Monticello wells [after Seeburger and Zoback, 1982]. The wells were drilled into late Paleozoic granodiorite bodies in the Charlotte Belt.

\section{Site ChARACTERISTICS}

Data from four wells are presented in this study. Two wells were drilled near the Monticello Reservoir in South Carolina (Figure 1) and two were drilled in the western Mojave Desert in southem California (Figure 2). The total depth of the wells varies between 580 and $1200 \mathrm{~m}$.

Fractures intersecting the borehole wall were detected using a borehole televiewer (BHTV). A detailed description of the BHTV operation is given by Zemanek et al. [1970]. Seeburger and Zoback [1982] present a detailed analysis of the macrocracks observed in these wells, and the results of their study will only be summarized here. The fractures observed on the BHTV logs probably do not represent the entire fracture population. Because the BHTV detects variations of well bore reflectivity, only those fractures which are held open to some degree, or which are filled with alteration minerals, will be detectable by the BHTV. Fractures that are partly or completely mineralized can be seen because the drilling process causes spalling of the rock near the fracture at the borehole. We use the term 'apparent aperture' when discussing measurements of fracture width because the aperture of the fractures measured from the BHTV log may not be directly related to conditions in the fracture away from the borehole wall. The televiewer can resolve features at the borehole wall with apparent apertures as small as $0.5 \mathrm{~mm}$. The BHTV log provides no information about the distribution of microcracks.

In South Carolina, wells MONT-1 and MONT-2 were drilled to depths of $1100 \mathrm{~m}$ and $1203 \mathrm{~m}$, respectively, in small plutons of granitic to granodioritic composition which were intruded into the Charlotte Belt metamorphic rocks of the Piedmont Province (Figure 1). Monticello Reservoir is the site of considerable reservoir-induced seismicity [see Talwani et al., 1980]. Most of the earthquakes in the vicinity of the reservoir are small $(M<2)$ events at extremely shallow depth $(<1-2 \mathrm{~km})$. In situ stress measurements in MONT-1 and MONT-2, the orientation of fractures in the wells, composite focal plane mechanisms, and the magnitudes of the events all suggest that thrust-type motion on fractures similar to many of those observed in the wells is responsible for this seismicity [Zoback and Hickman, 1982].

Figure 3 shows the density of macrofracturing as observed by the BHTV for the wells in this study. The depth to which casing extends in each well is indicated in the figure, and no information on fracture density is available for the cased sections. Fracturing in MONT-1 (Figure 3a) occurs in many small discrete zones distributed throughout the total depth of the well. In the lower 300 $400 \mathrm{~m}$ of the well there are fewer fractures, and the fractures are more evenly distributed. The upper $280 \mathrm{~m}$ of MONT-2 is highly fractured (Figure $3 b$ ), and another dense fracture zone extends from 450 to $500 \mathrm{~m}$. Several intense fracture zones are also seen in MONT-2 that span intervals of several tens of meters, and at nearly all depths, the fracture density in MONT-2 is greater than that in MONT-1. In both Monticello wells the majority of the fractures are steeply dipping. In MONT-1 most of the horizontal fractures occur only in the upper $200 \mathrm{~m}$; a few horizontal fractures are seen below $950 \mathrm{~m}$. In MONT-2 the horizontal fractures are concentrated in the upper $250 \mathrm{~m}$ and within the fracture zone from 400 to $500 \mathrm{~m}$.

The Crystallaire well (XTLR) and the Hi Vista well were drilled 4 and $34 \mathrm{~km}$, respectively, from the San Andreas fault near Palmdale in the western Mojave Desert (Figure 2). This portion of the San Andreas fault last ruptured in the great 1857 Fort Tejon earthquake. Many fractures intersect the XTLR well (Figure $3 c$ ), and the fracture density decreases slowly with increasing depth. Although localized fracture zones do occur in the XTLR well, numerous fractures are distributed throughout its entire depth, and the fracturing extends to the total depth of $869 \mathrm{~m}$. The fracture distribution in the Hi Vista well (Figure $3 d$ ) is somewhat anomalous compared to the other wells. A dense near-surface fracture zone extends to about $180 \mathrm{~m}$, the zone from 180 to 335

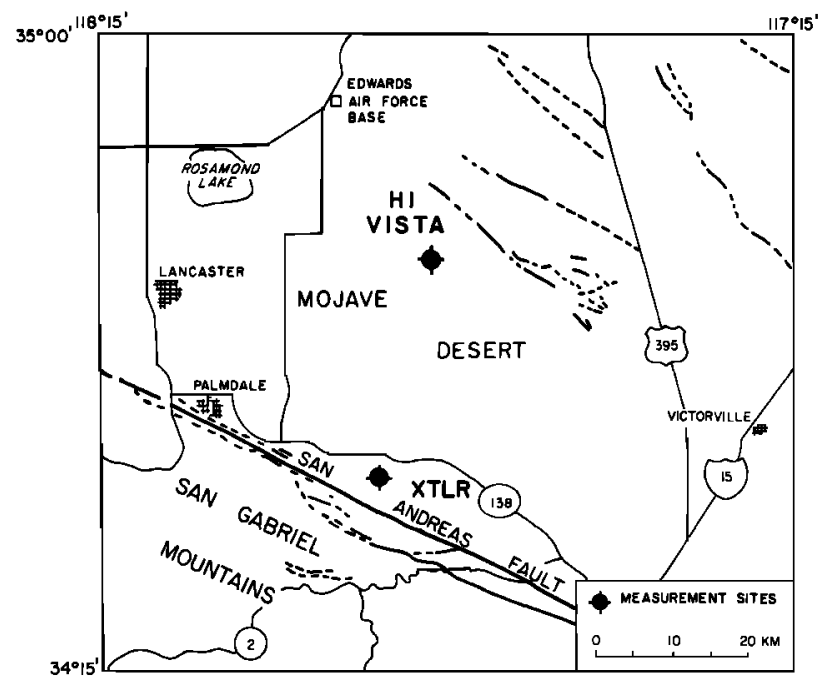

Fig. 2. Map showing the location of the Crystallaire and Hi Vista wells, which were drilled 4 and $34 \mathrm{~km}$, respectively, northeast of the San Andreas fault in the western Mojave Desert [after Seeburger and Zoback, 1982]. 
$\mathrm{m}$ is relatively unfractured, and from $335 \mathrm{~m}$ to the total depth of $584 \mathrm{~m}$ the fracture density is again quite high and roughly similar to that observed in the XTLR well. There are several zones of intense fracturing throughout the Hi Vista well, but the most intense (with the possible exception of the near-surface fractures obscured by the casing) is near the bottom. The majority of the fractures in both XTLR and Hi Vista are steeply dipping; almost no horizontal fractures are present in these wells.

By considering these four wells we can examine sonic velocity under conditions of widely varying fracture distributions. MONT1 is sparsely fractured, and the fracture density decreases slightly with increasing depth; MONT-2 is more highly fractured than MONT-1, especially in the upper $280 \mathrm{~m}$ and from 450 to $500 \mathrm{~m}$; the fracturing in the XTLR well is uniformly high and decreases slowly with increasing depth; the fracture density in the Hi Vista well is quite high at shallow depth and in the lower portion of the well.

\section{RESULTS}

\section{$P$ Wave Sonic Velocity}

Figures 4-7 show $P$ wave velocity and observed fracture density as a function of depth in the four wells. Figures 4,5 , and 7 also show $S$ wave velocity and $V_{p} / V_{s}$. The appendix contains a discussion of the method used in obtaining the sonic velocities shown in these figures. The sonic logs were run from the water table to the total depth in each well, except as noted below. In this section we present the results of the $P$ wave velocity measurements. The $S$ wave velocity data and $V_{p} / V_{s}$ will be discussed below.

Figures 4-7 also show the $P$ wave velocities in a representative sample from each well which was measured under confining pressure in the laboratory. The samples were evacuated and then saturated under 5 bars pore pressure. $P$ wave velocities were measured at a frequency of about $2 \mathrm{MHz}$ using a technique described by Peselnick and Stewart [1975]. Travel time could be measured

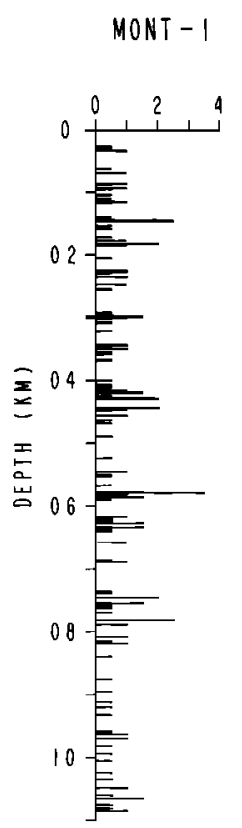

(A)

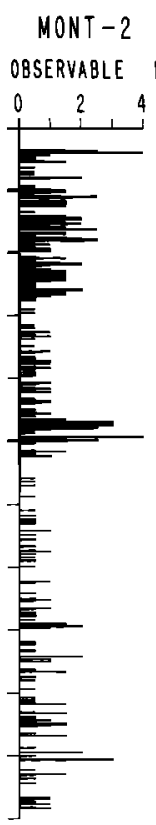

(B)

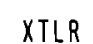

FRACTURES PER METER

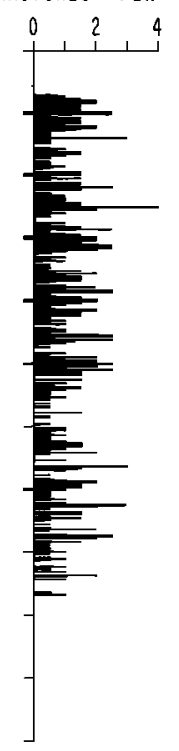

(C)
HI VISTA

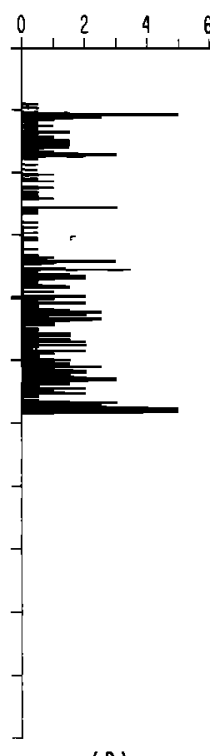

(D)
Fig. 3. The density of observable macroscopic fracturing as a function of depth for the four wells in this study. The fractures were picked from borehole televiewer records of the wells. The depth to which casing was set in each well is indicated by the upper shaded zone.

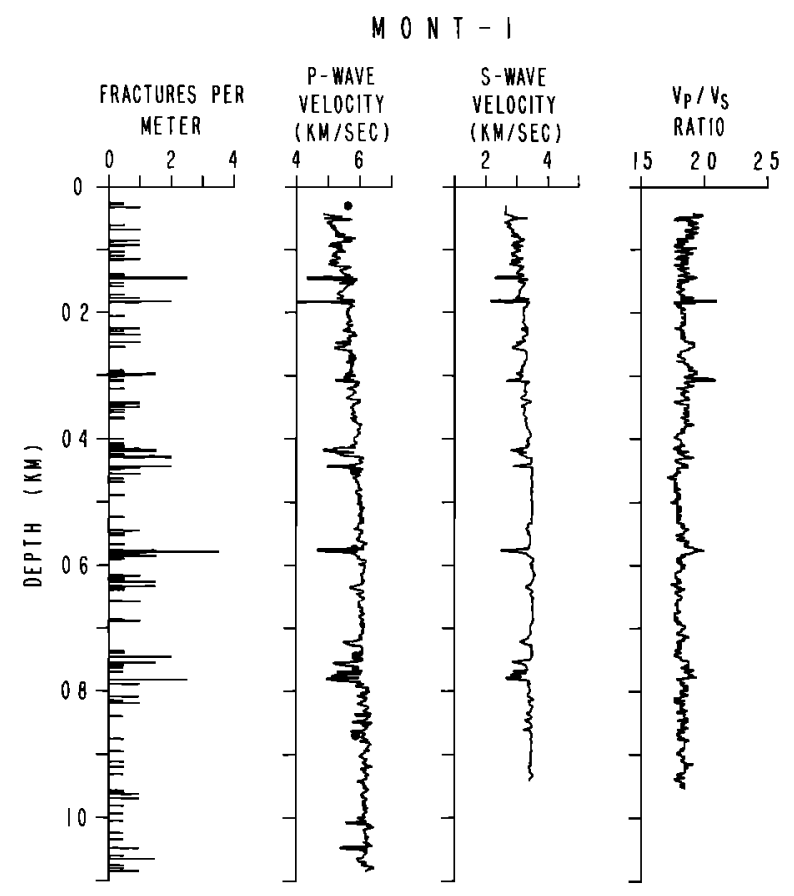

Fig. 4. Observable fracture density, $P$ wave velocity, $S$ wave velocity, and $V_{p} / V_{s}$ ratio as a function of depth for MONT-1. The solid circles show laboratory-determined $P$ wave velocities for one sample from 545 $\mathrm{m}$ in the well plotted as a function of depth by assuming an effective stress gradient of $16.7 \mathrm{MPa} / \mathrm{km}$.

to within $10 \mathrm{~ns}$, and the absolute accuracy of the measured velocities was about $\pm 0.5 \%$. Velocities were measured as a function of confining pressure with the pore pressure equal to atmospheric pressure. Pressure was converted to depth by assuming an in situ effective stress gradient of $16.7 \mathrm{MPa} / \mathrm{km}$, to correspond to the effective overburden stress. We think this conversion of pressure to depth is justified because (1) seismic velocity is essentially a function of the difference between confining pressure and pore pressure [Todd and Simmons, 1972], (2) the compressive stress in the direction of wave propagation (in this case the vertical stress) is most important in controlling $P$ wave velocity, as suggested by the results of Bonner [1974] and Lockner et al. [1977], and (3) the mean stress in all of these wells is approximately equal to the overburden stress [Zoback et al., 1980; Zoback and Hickman, 1982]. Direct comparison to the field data at every depth may not be valid, as the laboratory data are obtained from only one sample in each well. However, qualitative comparison of the sonic and ultrasonic velocities and the changes of those velocities with depth and pressure provides additional information about the mechanisms controlling velocity.

The in situ $P$ wave velocity in the MONT-1 well (Figure 4 ) increases from less than $5.4 \mathrm{~km} / \mathrm{s}$ near the surface to about $6.1 \mathrm{~km} / \mathrm{s}$ at $1100 \mathrm{~m}$. The $P$ wave velocity measured in a sample from a depth of $545 \mathrm{~m}$ increases from 5.7 to $6.0 \mathrm{~km} / \mathrm{s}$ over the appropriate pressure interval. Except for the highly fractured low-velocity intervals, the velocity log and the laboratory measurements agree quite well, although the laboratory measurements are slightly slower at depths greater than $500 \mathrm{~m}$. At the depth from which the sample was taken, the sonic and ultrasonic velocities are indistinguishable. There is a clear correlation between intervals of high fracture density and low sonic velocity. Almost every fracture zone is apparent as a low velocity zone on the sonic log.

The in situ $P$ wave velocities in MONT-2 (Figure 5) are more 


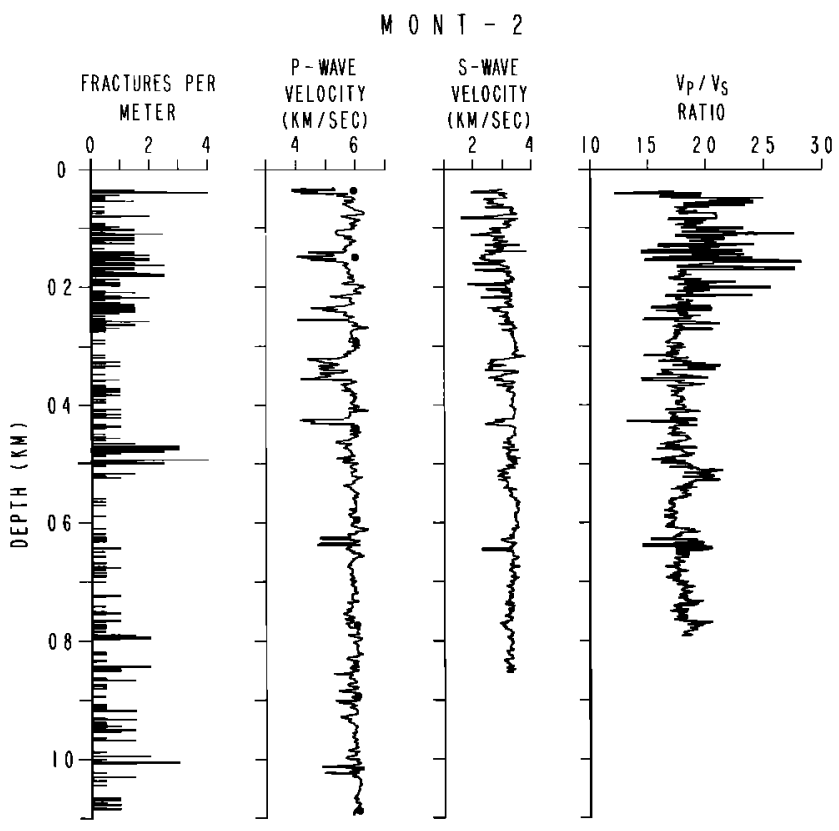

Fig. 5. Observable fracture density, $P$ wave velocity, $S$ wave velocity, and $V_{p} / V_{s}$ ratio as a function of depth for MONT-2. The solid circles show laboratory-determined $P$ wave velocities for one sample from 210 $m$ in the well plotted as a function of depth by assuming an effective stress gradient of $16.7 \mathrm{MPa} / \mathrm{km}$.

variable than in MONT-1, possibly due to the more intense fracturing, and the results are quite dissimilar. The $P$ wave velocity at shallow depth (about $5.9 \mathrm{~km} / \mathrm{s}$ ) is higher than in MONT-1, and the velocity increases only slightly with depth. Laboratory measurements on a sample from $210 \mathrm{~m}$ also show only a moderate increase of velocity with pressure (from 5.9 to $6.1 \mathrm{~km} / \mathrm{s}$ ). There is general agreement between the in situ and laboratory-determined velocities (with the exception of low-velocity intervals), although the laboratory-determined velocities are slightly higher than the in situ velocities at depths greater than $500 \mathrm{~m}$. As in MONT-1, the sonic and ultrasonic velocities at the sample depth are the same. The striking correlation between intervals of high fracture density and low $P$ wave velocity that was seen in MONT-1 is not obvious here, although relatively unfractured zones (e.g., $60-90 \mathrm{~m}, 270-$ $300 \mathrm{~m}$ ) have relatively higher velocity. The high uniform fracture density of the entire well appears to obscure the effect of local fracture zones on seismic velocity.

Figure 6 shows fracture density and $P$ wave velocity in the XTLR well. The uniformly high degree of fracturing in this well causes large variations in velocity. The measured velocity in the near-surface region is extremely low (about $3.5 \mathrm{~km} / \mathrm{s}$ ), and the velocity increases to an average value of only about $5.2 \mathrm{~km} / \mathrm{s}$ at $860 \mathrm{~m}$. The in situ velocity in XTLR is significantly lower than it is in MONT-1 and MONT-2, apparently due to the greater number of fractures. As in MONT-2, the numerous fractures in this well obscure the correlation between highly fractured intervals and low velocity, but zones with fewer fractures (e.g., at $270,560-610$, and $720 \mathrm{~m}$ ) have relatively high velocity. Laboratory measurements on a sample from the bottom of the well show an increase of velocity from 5.4 to $5.9 \mathrm{~km} / \mathrm{s}$ over the appropriate pressure range. Thus the laboratory measurements are markedly higher than the in situ velocities. The discrepancy between the laboratory and in situ velocities seems to decrease with depth. However, the sample velocity is significantly higher than the in situ velocity even at $869 \mathrm{~m}$, where the sample was taken.
Figure 7 shows the fracture density and $P$ wave velocity in the Hi Vista well. The velocities are higher here than at XTLR, and there is no increase in velocity with increasing depth. In fact, the velocity at $100 \mathrm{~m}$ (about $5.6 \mathrm{~km} / \mathrm{s}$ ) is higher than the velocity at $580 \mathrm{~m}$ (about $5.4 \mathrm{~km} / \mathrm{s}$ ) due to the numerous fractures near the bottom of the well. The highest velocity in the well was measured in the interval from 180 to $335 \mathrm{~m}$, where there are fewer fractures. Laboratory measurements on a sample from the bottom of the well show an increase of velocity from 5.6 to $5.9 \mathrm{~km} / \mathrm{s}$ over a pressure range corresponding to depths from $118 \mathrm{~m}$ to $588 \mathrm{~m}$. At the depth from which the sample was taken, the in situ velocity is markedly lower than the velocity measured in the sample.

A comparison between observed fracture density, in situ $P$ wave velocity, and the velocity measured in the laboratory is summarized in Table 1 . Several interesting trends emerge from these data. As might be expected, there is a correlation between the degree of fracturing in each well and the discrepancy between the laboratory and in situ values of the $P$ wave velocity at the depths from which the samples were taken. For both MONT-1 and MONT-2 the velocity measured in the laboratory is nearly identical to the velocity measured in the field, but in the XTLR well and the Hi Vista well, where there are many fractures, the in situ $P$ wave velocity is substantially lower than would be expected from laboratory measurements. However, the relative magnitudes of the ultrasonic velocities measured in samples from each well are the same as the relative magnitudes of the velocities measured in situ. The sample with the largest ultrasonic velocity (MONT-2) comes from the well in which the highest sonic velocity was measured. The fact that the in situ velocity is higher at MONT-2 than at MONT-1, even though MONT-2 is highly fractured, suggests that, though macrofractures lower the velocity in

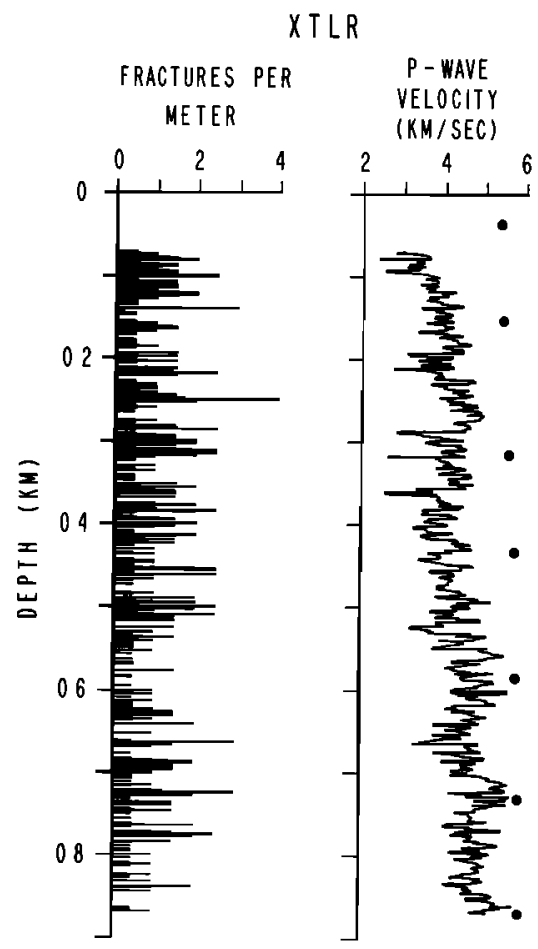

Fig. 6. Observable fracture density and $P$ wave velocity as a function of depth for the XTLR well. The solid cirlces show laboratory-determined $P$ wave velocities for one sample from the bottom of the well at $869 \mathrm{~m}$ plotted as a function of depth by assuming an effective stress gradient of 16.7 $\mathrm{MPa} / \mathrm{km}$. The high degree of fracturing in this well made measurements of $S$ wave velocity unreliable. 


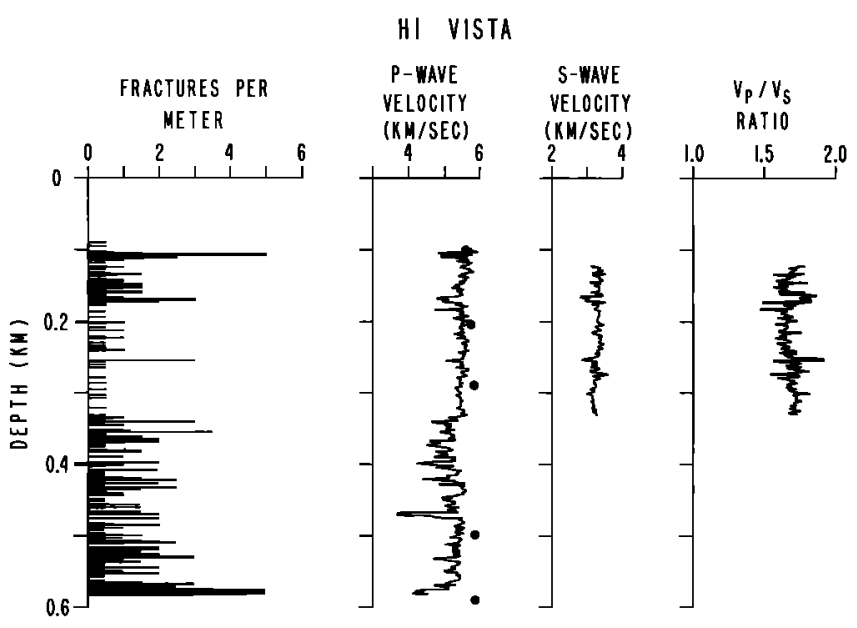

Fig. 7. Observable fracture density, $P$ wave velocity, $S$ wave velocity, and $V_{p} / V_{s}$ ratio as a function of depth for the Hi Vista well. The solid circles show laboratory-determined $P$ wave velocities for one sample from the bottom of the well at $584 \mathrm{~m}$ plotted as a function of depth by assuming an effective stress gradient of $16.7 \mathrm{MPa} / \mathrm{km}$. No $S$ wave $\log$ was obtained for the lower portion of the Hi Vista well due to the high degree of fracturing.

a given well, the degree of in situ fracturing cannot be unambiguously estimated from in situ $P$ wave velocity because of the importance of composition and microcracks.

The increase of velocity with pressure in the laboratory samples is related to the increase of velocity with depth in the field. The core from MONT-2 has the lowest increase in velocity with pressure and the smallest increase in velocity with depth in situ. The change in velocity with depth is greatest at XTLR; the core from XTLR also exhibited the largest increase in velocity with pressure. For these three wells the in situ velocity increase is equal to or greater than the increase measured in the laboratory, although at the Hi Vista well the anomalous fracture distribution masks the expected velocity increase.

\section{Vertical Seismic Profile}

Because the wavelength of the energy from the sonic tool (20$60 \mathrm{~cm}$ ) is similar to the spacing of many of the fractures, the frequency at which velocity is measured must be taken into account when sonic logs are analyzed. For example, field measurements of velocity using seismic refraction, reflection, or downhole surveys are made at frequencies that are several orders of magnitude lower than the frequencies of sonic logs. As the spacing of the macrofractures is similar to the sonic wavelength, but many orders of magnitude smaller than the wavelengths used in seismic experiments, the effect of the macrofractures on each measurement may be quite different.

Comparisons of seismic velocities over a wide frequency range are also complicated by the possible effects of dispersion. Recent laboratory measurements [Spencer, 1981; Murphy, 1982] have shown that there can be significant velocity dispersion in the frequency band from $10 \mathrm{~Hz}$ to $10 \mathrm{kHz}$ in a wide variety of rocks. Although confining pressure moderates this effect, the change in Young's modulus (E) over this frequency range was about $22 \%$ for Oklahoma granite at room conditions [Spencer, 1981]. Although Spencer suggests that this large effect on $\mathrm{E}$ was due primarily to stress relaxation in the shear modulus, this effect may still be large enough to affect measurements of $P$ velocity.

In order to study the possible effects of frequency due to dispersion and of the finite size of the macrofracture in the rock volume sampled by the sonic wave, a vertical seismic profile (VSP) was run at XTLR using an air gun source. The air gun has a fundamental frequency of about $75 \mathrm{~Hz}$. Interval velocities were calculated by differencing the arrival times to a geophone placed at $30-\mathrm{m}$ intervals in the well (see appendix for further details). By summing the travel times measured by the sonic tool over these intervals, a comparison can be made between the velocity measured by the sonic tool over $30.5-\mathrm{cm}$ intervals and the velocity calculated from the VSP (Figure 8). The interpretation of a nearby seismic refraction experiment with a fundamental frequency near $10 \mathrm{~Hz}$ (G. Fuis, personal communication, 1982) is plotted in Figure $\mathbf{8}$ for comparison. Overall, there is remarkable agreement between the sonic $\log$ (with 20 - to $60-\mathrm{cm}$ wavelengths), the vertical seismic profile (with wavelengths of about $60 \mathrm{~m}$ ), and the refraction survey (at wavelengths of several hundred meters). However, the ultrasonic velocities (also shown in figure 8) are significantly higher than the field measurements.

The field measurements of velocity shown in Figure 8 indicate that dispersion in the range of frequencies from $10 \mathrm{~Hz}$ to $20 \mathrm{kHz}$ is less than $10 \%$, which is the combined accuracy of our measurements (see appendix). Interestingly, the velocity measured by the sonic $\log$ in XTLR is slightly lower than that measured by the VSP, and this difference cannot be explained by dispersion.

It is difficult to determine whether the discrepancy between the $\log$ velocities and the laboratory measurements is in part due to dispersion. However, in both MONT-1 and MONT-2 there is close agreement between log velocities and laboratory measurements. Therefore velocity dispersion over frequencies from 20 $\mathbf{k H z}$ to $2 \mathrm{MHz}$ is probably small. However, the presence of many fractures in XTLR and Hi Vista causes large discrepancies between the $P$ wave velocity measured in a 5-cm-long core and the $\log$ velocities. Thus it appears that the differences between the in situ data at the sample depth and the laboratory measurements result primarily from the presence of the macrofractures, and it appears that the effect of fractures on $P$ wave velocities is roughly the same over the bandwidth from $10 \mathrm{~Hz}$ to $20 \mathrm{kHz}$.

\section{S Wave Sonic Velocities}

Figures 4,5 , and 7 show $S$ wave velocities and $V_{p} / V_{s}$ measured at MONT-1, MONT-2, and in the upper portion of Hi Vista. Be-

TABLE 1. Laboratory-Determined $V_{p}$, in Situ $V_{p}$, and in Situ Macrofracturing for MONT-1, MONT-2, XTLR, and Hi Vista

\begin{tabular}{lcccc}
\hline & MONT-1 & MONT-2 & XTLR & Hi Vista \\
\hline $\begin{array}{l}\text { Relative fracture } \\
\text { density }\end{array}$ & low & medium & high & high \\
$\begin{array}{l}\text { In situ velocity } \\
\text { Laboratory velocity }\end{array}$ & $5.4-6.1(14 \%)$ & $5.9-6.1(3 \%)$ & $3.5-5.2(49 \%)$ & $5.6-5.4(-4 \%)$ \\
\hline
\end{tabular}

Numbers in parentheses are the percent change of velocity with pressure or depth over the measured interval. 


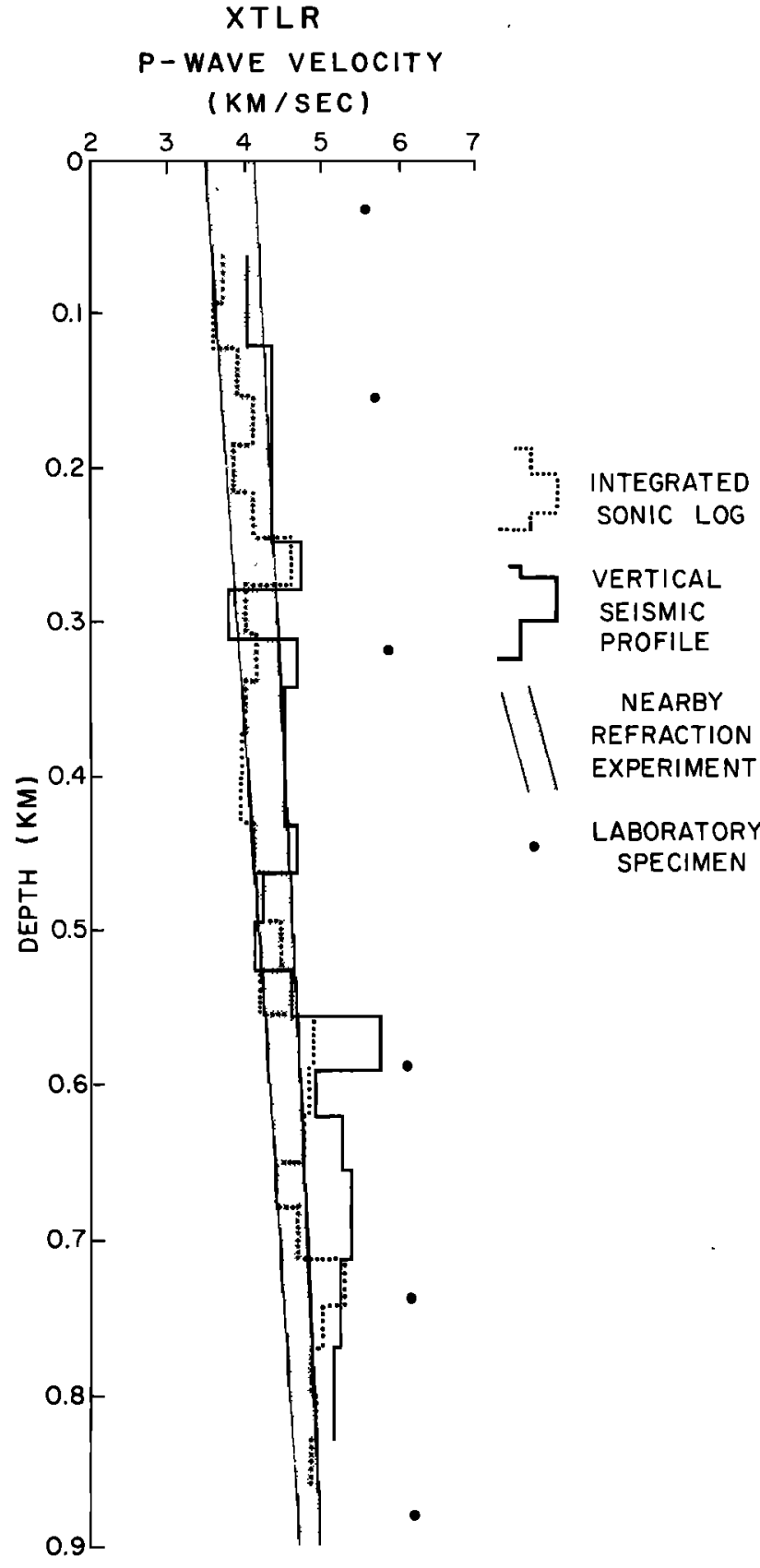

Fig. 8. Comparison of compressional velocity as a function of depth at the XTLR well for three different in situ measurements. Interval velocities from the downhole survey (fundamental frequency $75 \mathrm{~Hz}$ ) are plotted as a solid line. The dotted line shows velocities measured by the sonic logging tool at $10-20 \mathrm{KHz}$ averaged over the same intervals. The shaded area is bounded by two velocity-depth functions fitted to the data from a nearby refraction survey (fundamental frequency $10 \mathrm{~Hz}, \mathrm{G}$. Fuis, personal communication, 1982). Laboratory-determined $P$ wave velocity of a core from the bottom of the well is also shown for comparison. Note that all three in situ measurements of velocity agree quite well and are markedly lower than the laboratory- determined velocity.

cause of the high fracture density at XTLR and in the lower portion of Hi Vista it was not possible to record $S$ wave logs. The method used to obtain these logs is described in the appendix.

Figure 4 shows $S$ wave velocity and $V_{p} / V_{s}$ ratio in MONT-1. The near-surface $S$ wave velocity is about $2.8 \mathrm{~km} / \mathrm{s}$, and the velocity increases with depth to about $3.4 \mathrm{~km} / \mathrm{s}$ in the lower portion of the well. The correlation between intervals of high fracture density and low velocities seen in the $P$ wave $\log$ is also present in the $S$ wave $\log$. The $V_{p} / V_{s}$ ratio in MONT-1 is about 1.9 in the near-surface region and decreases gradually with increasing depth to about 1.8 in the lower portion of the well. The $V_{p} / V_{s}$ ratio also is strongly affected by the presence of fractures; the fracture zones at $180,290-310$, and $580 \mathrm{~m}$ have $V_{p} / V_{s}$ ratios greater than 2.0.

Figure 5 shows $S$ wave velocity and $V_{p} / V_{s}$ ratio in MONT-2. The $S$ wave velocity is quite low and highly variable in the highly fractured interval above $280 \mathrm{~m}$. The average velocity for the zone below $280 \mathrm{~m}$ is $3.35 \mathrm{~km} / \mathrm{s}$ and decreases slightly below $600 \mathrm{~m}$. Zones where the $P$ wave velocity is low are also zones of low $S$ wave velocity (for example, at $300-330 \mathrm{~m}$ and $400-410 \mathrm{~m}$ ). In general, unfractured zones have the highest $S$ wave velocities (510-590 $\mathrm{m})$, and in these zones the percentage increase in $S$ wave velocity is more pronounced than for $P$ wave velocity. There is more scatter in $V_{p} / V_{s}$ because either spurious $P$ or $S$ wave velocities result in large variations of the ratio. In the densely fractured upper portion of MONT-2 the $V_{p} / V_{s}$ ratio varies from 1.75 to more than 2.0 . Below $280 \mathrm{~m}$ the $V_{p} / V_{s}$ ratio varies between 1.65 and 1.95 (except in isolated sections) and seems to increase slightly with increasing depth. Several fractures seem to coincide with locally large $V_{p} / V_{s}$ ratios (for example, for fractures in the zone from 193 to $270 \mathrm{~m}$ ). However, from 320 to $370 \mathrm{~m}$ and from 510 to $560 \mathrm{~m}$, high $V_{p} / V_{s}$ ratios are seen in relatively unfractured rocks. In the interval from 320 to $370 \mathrm{~m}$ both $P$ and $S$ wave velocities are anomalously low, but in the interval from 510 to $560 \mathrm{~m}$, only the $S$ wave velocity is low. Furthermore, several fractured intervals are not clearly associated with higher $V_{p}$ $V_{s}$ ratios.

$S$ wave velocity and $V_{p} / V_{s}$ ratio in the upper part of the Hi Vista well are shown in Figure 7. The $S$ wave velocity in the upper 400 $\mathrm{m}$ is about $3.4 \mathrm{~km} / \mathrm{s}$ and decreases slightly with increasing depth. There is no clear relationship between distinct fracture zones and $S$ wave velocities. $V_{p} / V_{s}$ is about 1.65 in the upper $200 \mathrm{~m}$ and increases slightly to 1.8 in the lower section. Densely fractured zones are again characterized by large variations in the calculated $V_{p} / V_{s}$ ratio. The prominent fracture zone at $256 \mathrm{~m}$ has a $V_{p} / V_{s}$ ratio of 1.9 , much higher than that of the rest of the well. As in MONT-2, several fracture zones seem to have locally higher $V_{p}$ $V_{s}$ ratios, although many do not.

\section{Sonic Waveforms}

In order to study in more detail the effect of in situ fractures on $V_{p}$ and $V_{s}$, full waveforms were recorded at the Hi Vista well with the sonic tool stationary in the well. The first $10 \mathrm{~ms}$ of each waveform was digitized at $5-\mu s$ intervals. Waveforms were recorded every $30.5 \mathrm{~cm}$ over a $30-\mathrm{m}$ interval that included both fractured and unfractured sections of the well.

Figures 9 and 10 show data from two intervals in the Hi Vista well. At the left side of each figure is the BHTV record of the interval. $V_{p}$ and $V_{s}$ calculated from the sonic logs at $30.5-\mathrm{cm}$ intervals are shown in the center of each figure. The data points are plotted at the upper end of the interval over which differential travel time was measured. Where the travel times were picked incorrectly, velocities were calculated from arrival times picked on the full waveforms and are denoted by crosses. Also plotted in these figures is the $V_{p} / V_{s}$ calculated from the velocity data. Full waveforms from the receiver at a distance of $1.22 \mathrm{~m}$ from the source are displayed at the right side of each figure. The waveforms are plotted at the receiver depth. Since the source is 


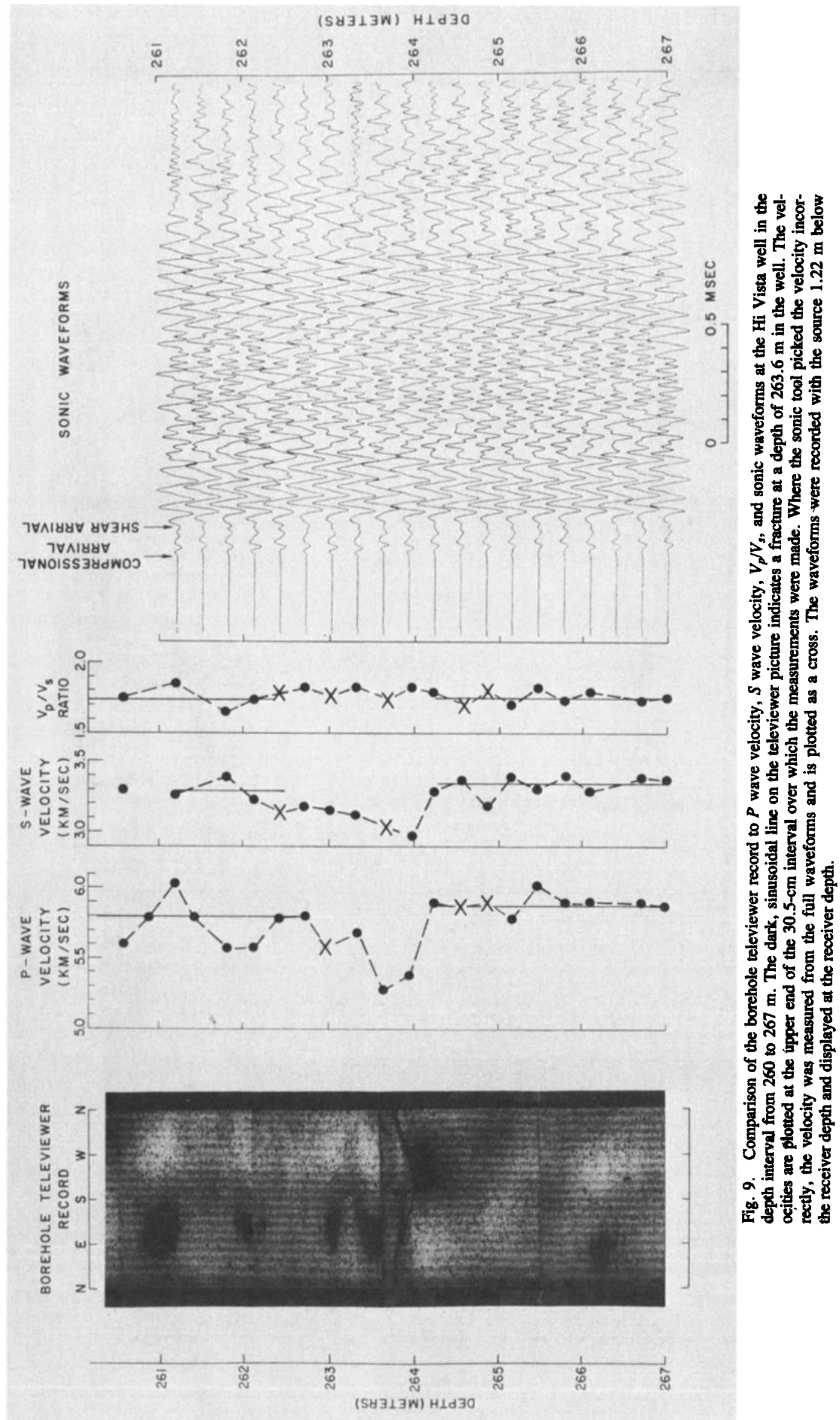



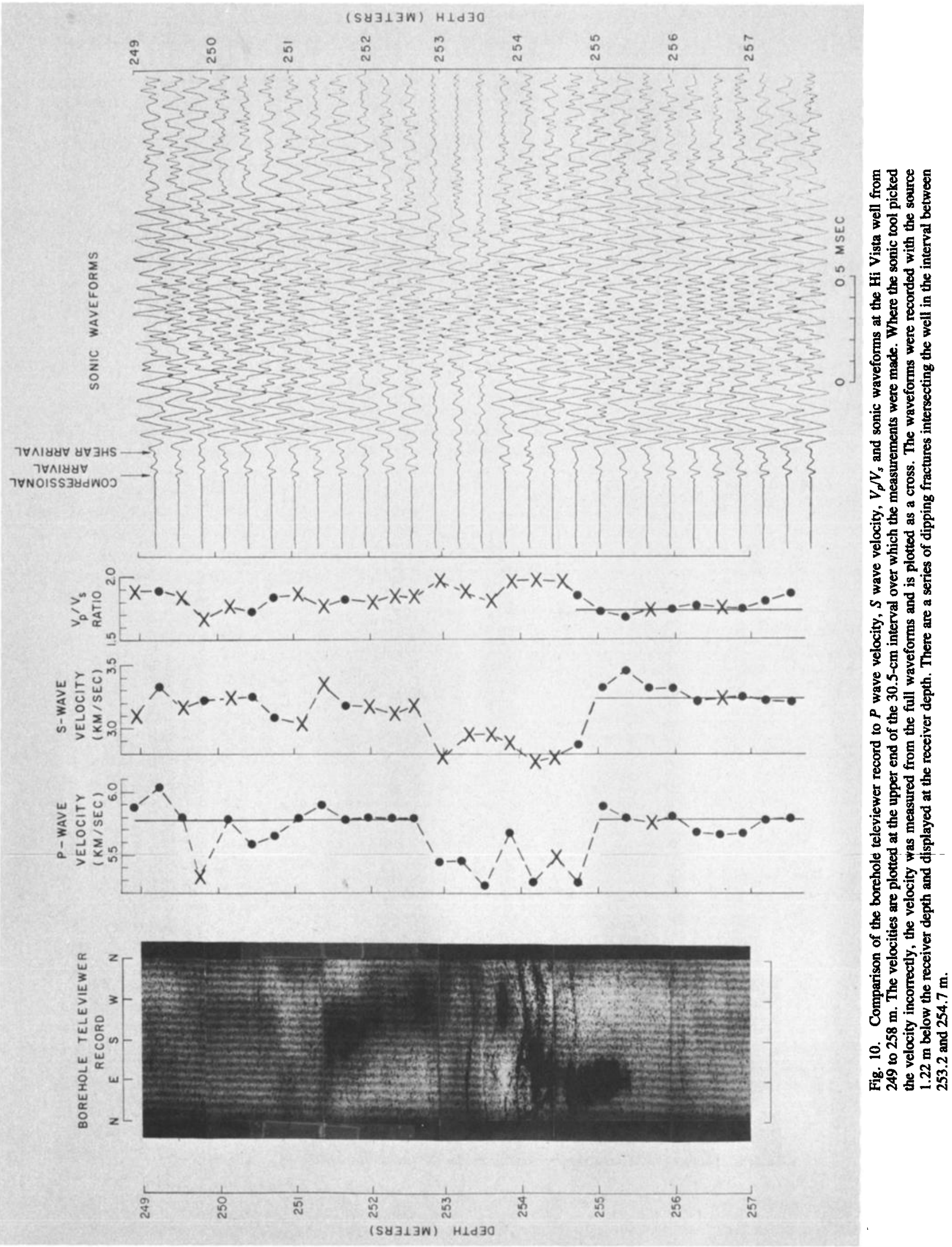
below the receiver, the travel path extends over the $1.22-\mathrm{m}$ interval below the plotted depth.

Figure 9 shows data from the depth interval between 260 and $267 \mathrm{~m}$. A single macroscopic fracture intersects the borehole at $263.6 \mathrm{~m}$, striking $\mathrm{N} 45^{\circ} \mathrm{W}$ and dipping $40^{\circ}$ to the southwest. The apparent aperture of the fracture is about $8 \mathrm{~mm}$, although this could be misleading if drilling causes spalling of the rock near the fracture at the borehole. The average $P$ wave velocity above the fracture is about $5.80 \mathrm{~km} / \mathrm{s}$, and the average velocity below the fracture is about $5.88 \mathrm{~km} / \mathrm{s}$. The average $S$ wave velocity above the fracture is about $3.30 \mathrm{~km} / \mathrm{s}$ and about $3.35 \mathrm{~km} / \mathrm{s}$ below the fracture. This yields average $V_{p} / V_{s}$ ratios of 1.73 and 1.76 above and below the fractured interval, respectively. The fracture clearly reduces both $V_{p}$ and $V s$; the principal reduction in velocity occurs over about a $1-\mathrm{m}$ zone straddling the fracture. Importantly, the anomalously low velocity is not confined to travel paths intersecting the fracture plane. Also, the $V_{p} / V_{s}$ ratio seems to be slightly increased in a broad zone surrounding the fracture.

The fracture at $263.6 \mathrm{~m}$ has little effect on the character of the waveforms displayed at the right. The arrivals below $264 \mathrm{~m}$, which do not cross the fracture, are remarkably uniform. Both $P$ and $S$ amplitude are essentially unaffected by the fracture. Some subtle distortion, particularly in the $S$ waveform, occurs in waveforms in the interval from 262 to $263.8 \mathrm{~m}$, which cross the fracture, and the $S$ arrival is slightly delayed. The compressional arrival time is quite variable near the fracture $(262-263.8 \mathrm{~m})$ and in general shows slightly more scatter than the shear arrival time over the entire interval. The fracture does not significantly affect the character of later arrivals.

Figure 10 shows a more intensely fractured zone at $254 \mathrm{~m}$ in the Hi Vista well. This fracture zone can also be seen in Figure 6; the sonic logs show sharply reduced $V_{p}$ and $V_{s}$ and sharply increased $V_{p} / V_{s}$. The average values of $V_{p}, V_{s}$, and $V_{p} / V_{s}$ over the entire interval are identical to those obtained for the upper section of Figure 8. As in Figure 8, $P$ wave velocity is reduced in both the fracture zone and the area adjacent to the fracture zone where the travel path does not intersect any apparent macrofractures. The $S$ waves were so badly attenuated by the fractures that velocities could not be determined by the sonic logging tool, although one markedly lower velocity was detected in the fracture zone. Velocities were calculated for intervals where the sonic log does not provide any data by picking arrival times from waveforms recorded at the two near receivers. The $S$ wave velocity determined from the full waveforms is also measurably lower near the fracture zone, and $V_{p} / V_{s}$ is higher. Although the largest velocity reduction occurs within the fracture zone, changes in $V_{p}$, $V_{s}$, and $V_{p} / V_{s}$ extend at least $1 \mathrm{~m}$ above the fractures.

The fracture zone shown in Figure 10 causes significant distortion of the wave field. Compressional and shear energy is sharply reduced, and the arrivals are delayed significantly. The fracture zone also severely attenuates later arrivals, although the high-frequency direct fluid wave is unaffected.

\section{Discussion}

It is well known that the presence of flat cracks or pores in an otherwise homogeneous material can substantially reduce its elastic moduli (and hence velocities). Microcracks in rock have been successfully invoked to explain laboratory velocity measurements as a function of confining pressure [Birch, 1961], pore pressure [Todd and Simmons, 1972], and saturation [Nur and Simmons, 1969]. O' Connell and Budiansky [1974] theoretically deduced the effect that cracks should have on elastic moduli and seismic velocity, using a self-consistent model that is reasonable for a densely fractured medium where crack interaction is important. The model is formulated under the assumption that both matrix and crack distribution are isotropic and that the cracks are much smaller than the seismic wavelength. Qualitatively, the $O^{\prime}$ Connell and Budiansky [1974] model predicts that for saturated cracks an increase in spatial crack density increases $V_{p} / V_{s}$ and decreases $V_{p}$ and $V_{s}$.

In this discussion we concentrate on changes in the elastic moduli because density changes due to fracturing probably had a negligible effect on $P$ and $S$ wave velocity as (1) the presence of fractures would probably decrease the density of the aggregate, causing the velocity to increase, and (2) the functional dependence of velocity on density is the same for both $P$ and $S$ waves, so the ratio of the velocities will be independent of density.

The results presented here indicate that sonic velocities measured in boreholes are affected by macrofractures in a way similar to that predicted by $O^{\prime}$ Connell and Budiansky [1974] for the effect of microcracks on velocity. That is, increased macrofracture density decreases $V_{p}$ and $V_{s}$ and increases $V_{p} / V_{s}$. However, the situation discussed here differs from that described by the $O^{\prime} C o n$ nell and Budiansky [1974] model in several fundamental ways. Because the macrofractures are large in comparison to the sonic wavelength, the aggregate including macrofractures cannot be considered as an ideal continuum. Also, as the macrofractures occur singly or in preferentially oriented clusters, they impart an anisotropy to the aggregate that is not adequately modeled by O'Connell and Budiansky [1974]. Therefore it is unlikely that the model generally provides an adequate explanation for the effect of macrofractures on sonic velocity. It is interesting, however, that in one well (XTLR) the effect of the fractures on the sonic velocity is quite similar to the effect of the fractures on seismic velocity (see Figure 8). As the fractures in aggregate have a variety of orientations in this well [Seeburger and Zoback, 1982] and as the seismic wavelengths are several orders of magnitude larger than the fracture size, the $O^{\prime}$ Connell and Budiansky [1974] model probably can be used to describe the major features of the effect of the macrofractures on seismic velocity.

Let us now consider three conceptual models for macroscopic fractures, shown schematically in Figure 11 . We assume, in all three cases, that granular debris, vein-forming minerals, or asperities are holding the fractures open under pressure and the fractures are observable only because the fracture faces are held apart. In the spring model a macroscopic fracture acts essentially like a compliant element in an elastic continuum. That is, there is no change in the elastic properties of the rock adjacent to the fracture. This macrofracture model can be simulated by the introduction of saw cuts in intact laboratory specimens. Stesky [1979] found that saw cuts in a low-porosity sample significantly lowered the velocity and increased the pressure dependence of velocity of the sample.

In the microfracture model the rock adjacent to the fracture is a zone of relatively intense microcracking, but otherwise little change has occurred in the rock. Thompson [1966] found zones of high fracture density adjacent to principal slip surfaces in granites. The increased crack density in these zones was believed to have developed during slip events. The presence of slickensides on fracture surfaces in samples taken at depth from both the XTLR well and Hi Vista is evidence that the fractures observed at depth have accommodated shear motion, and increased microcrack density may have resulted from that motion. Alternatively, 


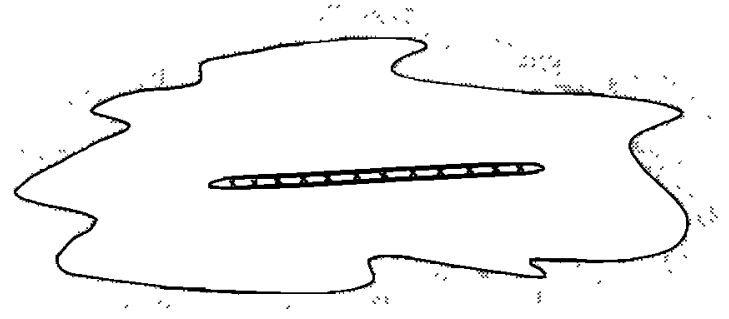

\section{Spring Model}

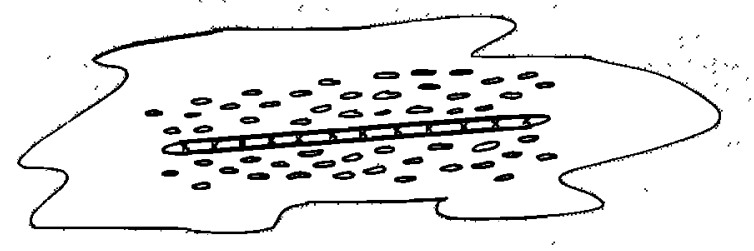

\section{Microfracture Model}

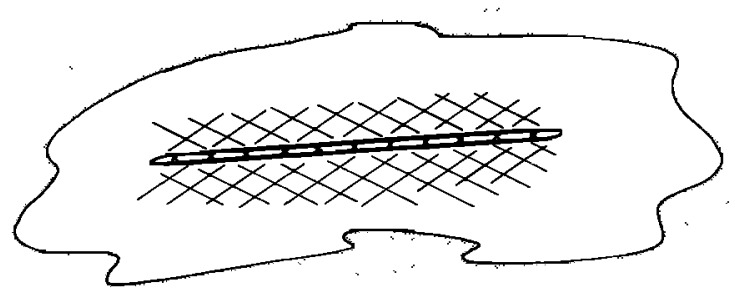

\section{Alteration Model}

Fig. 11. Schematic representation of the three models of an in situ macrofracture. In the spring model the fracture is an elastic inclusion whose presence does not affect the properties of the surrounding matrix. In the microfracture model the fracture has accommodated shear motion resulting in additional microcracking of the matrix surrounding the fracture, and in the alteration model the matrix around the fracture is more highly altered than the host rock due to transmission of fluids through the fracture.

the fracture we see may be the end product of an episode of crack growth that initially produces a large number of microcracks some of which then coalesce to produce the observed macrofracture.

In the alteration model the rock adjacent to the fracture has been mechanically and chemically altered so as to reduce the elastic moduli. Weathering can reduce the velocities of granites near the surface, and deep weathering is observed in granitic terranes where fractures provide conduits for surface water [Thomas, 1974]. Analysis of cores from MONT-2 (D. Prowell, written communication, 1982) indicates that significant alteration is associated with the fractures in that well. Cuttings from the $\mathrm{Hi}$ Vista and XTLR wells also show the effects of weathering, particularly in the upper $100 \mathrm{~m}$ of the Hi Vista well (D. Stierman, written communication, 1982). A core from the bottom of the XTLR well, just below the fracture zone at $869 \mathrm{~m}$, is highly altered, suggesting that weathering has extended to considerable depths.

Now let us consider the sonic log data in terms of the three conceptual models shown in Figure 11. The log data show that both compressional and shear wave velocities are reduced by macroscopic fractures in situ. In the case of relatively unfractured rock intervals the effect of localized fractures is to reduce the $P$ and $S$ wave velocities and increase $V_{p} / V_{s}$. In more highly fractured rock, in situ $\boldsymbol{P}$ wave velocities are lower than the ultrasonic velocities of intact samples in the laboratory (Figures 6 and 7). Both Figure 6 and Figure 7 suggest that the difference between the laboratory and in situ $P$ wave velocities increases with fracture density. The difference in velocities gradually decreases as the macroscopic fracture density decreases with depth in Figure 6 , and the difference increases with depth as the macrofracture density increases in Figure 7. Both of these cases suggest that in densely fractured rock the presence of macrofractures lowers the bulk elastic moduli of the rock. Importantly, anomalously low velocities are seen in Figures 4, 9, and 10 in the zones adjacent to the macroscopic fractures. Thus the macroscopic fracture has apparently affected the matrix properties of the rock surrounding it in a manner consistent with either the alteration model or the microcrack model.

Although the alteration and microcrack models are similar, the microcrack model predicts that there is a correlation between macrofracture and microcrack densities. If wells with the highest macrofracture density also had the greatest number of microcracks, one would therefore expect those wells to have the largest increase of velocity with depth. This is not the case, as comparison of the change of velocity with depth in MONT-1 and MONT2 clearly shows. In fact, as shown in Table 1 , laboratory velocities seem to be more pressure-dependent in samples from wells in which $P$ wave velocity increases significantly with depth (MONT-1 and XTLR). Therefore although microcracks affect velocities both in situ and in the laboratory, there does not seem to be a simple correlation between the degrees of macrofracture and microcrack density in these wells. Thus it is unlikely that enhanced microcracking near the macrofractures alone can adequately explain the observed data.

A surprising result of this study is that it is not possible to simply relate fracture density to $P$ wave velocity or the change in $P$ wave velocity with pressure in granitic rocks. As shown in Table 1 , although MONT-2 is more fractured than MONT-1, it has a higher $P$ wave velocity. The Hi Vista well is fractured similarly to the XTLR well at shallow depth but has a higher $P$ wave velocity. Thus even though the presence of macrofractures has a marked effect on $\boldsymbol{P}$ wave velocity, the effects of composition and microfractures are also very important. This may explain why there are zones of anomalously low velocities in MONT-2 (Figure 5) which were not accompanied by obvious macrofracturing. It appears that at a given site one could probably not expect to predict approximate relative fracture densities from either $P$ wave velocity or the change in velocity with depth.

Interestingly, fracture orientation does not appear to play a strong role in influencing the effect of fractures on sonic velocities in these wells. As the sonic travel path is vertical, one might expect that near-horizontal fractures would have a stronger effect on the velocities than would fractures with dips greater than $45^{\circ}$. In MONT-1, however, where no horizontal fractures occur between 200 and $950 \mathrm{~m}$, the effect of the steeply dipping fractures within that interval was as strong as the effect of the more gently dipping fractures at shallower depths. In XTLR, where almost no horizontal fractures are seen, the in situ velocity was significantly reduced by the fractures even though most of the fractures had dips greater than $45^{\circ}$. Thus our data do not show any simple relationship between fracture dip and the degree to which the fracture affects sonic velocities.

The suspicion that fracture zones in the crust could be zones of 


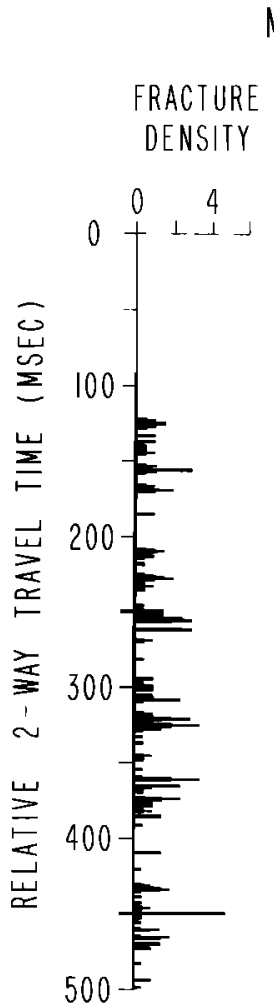

MONT-I

P-WAVE

VELOCITY SYNTHETIC

(KM/SEC)

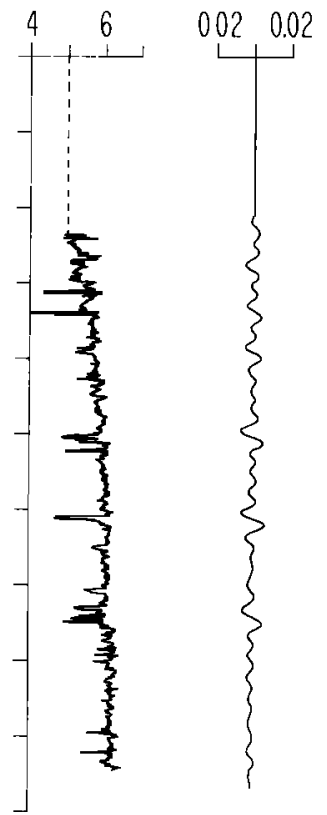

(A)
MONT - 2

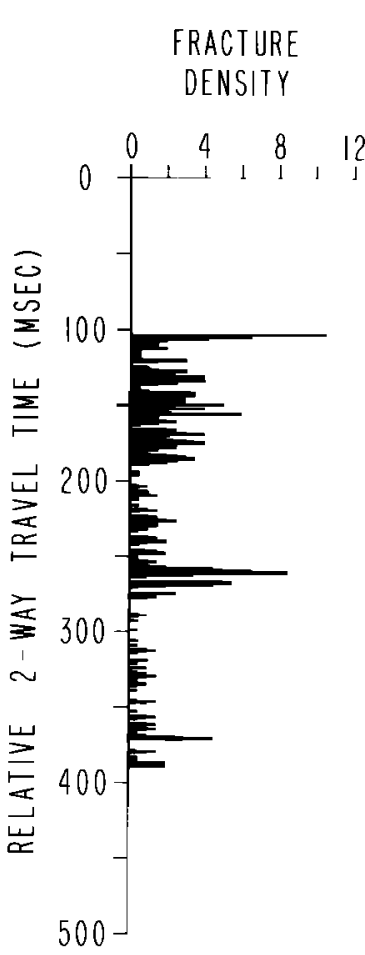

P- WAVE

VELOCITY SYNTHETIC $(K M / S E C)$

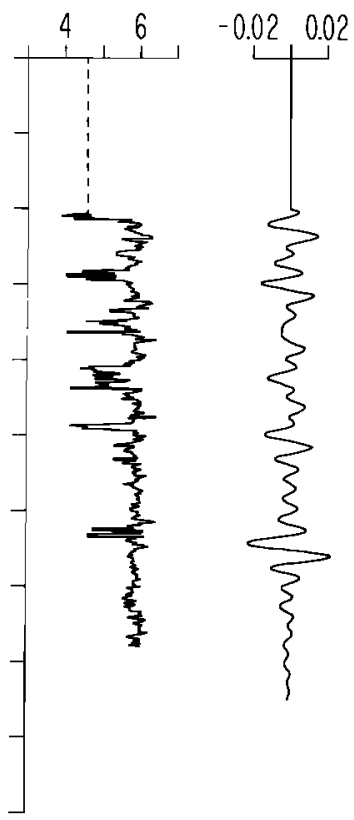

(B)

HI VISTA

$X T L R$
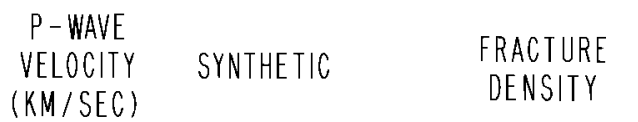

P- WAVE

VELOCITY

(KM/SEC)

SYNTHETIC
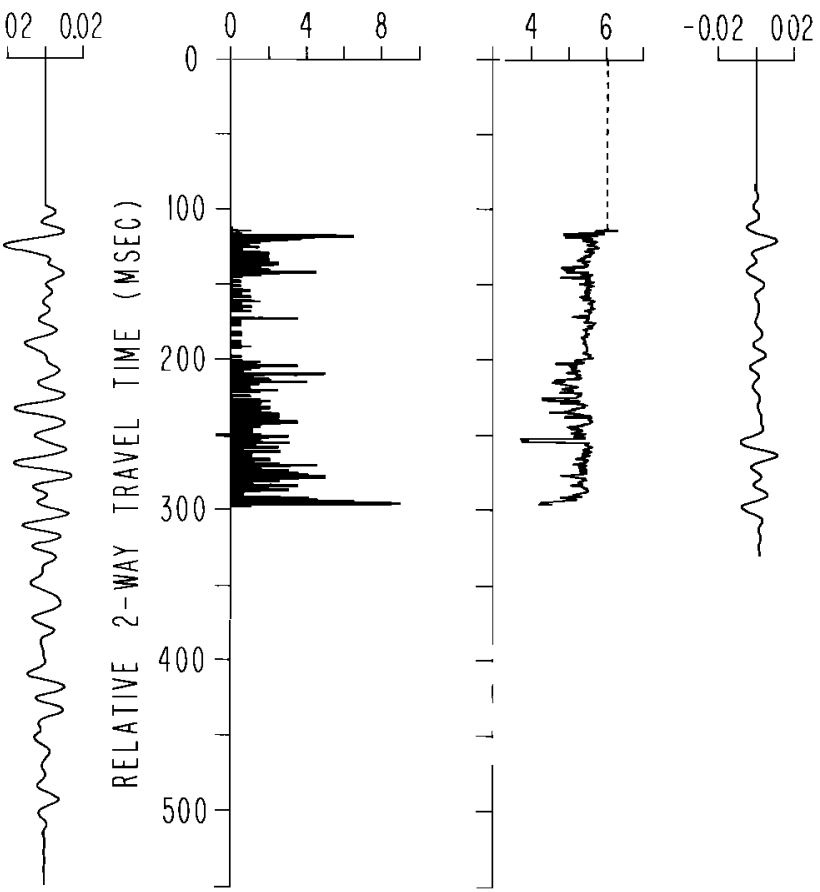

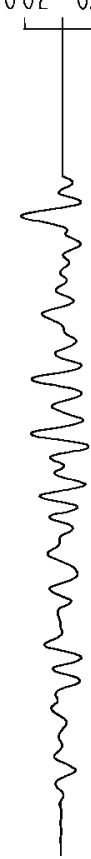

(C)

Fig. 12. Synthetic reflection seismograms for (a) MONT-1, (b) MONT- 2, (c) XTLR, and (d) Hi Vista, plotted as a function of two-way travel time. The fracture density and seismic velocities are also plotted as a function of travel time. The synthetic amplitudes are scaled by the maximum amplitude of the source waveform. 
low seismic velocities has led to the suggestion that fracture zones could be the cause of reflection events observed within otherwise homogeneous crystalline rocks. Mair and Green [1981] have identified a series of gently dipping fracture zones as the source of several strong events on a high-resolution seismic reflection profile in the Lac du Bonnet batholith of the Canadian Shield. Fracture zones have also been suggested as the source of crustal reflections at much greater depths [Lynn, 1979; Schilt et al., 1979]. The Wind River Thrust Zone as observed on COCORP profiles [Smithson et al., 1978] has been traced to more than $20 \mathrm{~km}$ depth. The fault zone is a strong reflector even where there is crystalline rock on both sides of the fault. Jones and Nur [1982] conclude that mylonitization of the country rock, which may accompany large shear displacements at depth, cannot produce reflections of sufficient amplitude to explain the data. They suggest that high pore pressures in cracks along the fault zone may reduce the velocities and thus cause the reflections.

To examine these ideas, synthetic reflection seismograms were calculated from the velocity logs. The reflection coefficient series was calculated from the velocity logs at $30.5-\mathrm{cm}$ intervals using the formula $R=\left(\rho_{1} V_{1}-\rho_{2} V_{2}\right) /\left(\rho_{1} V_{1}+\rho_{2} V_{2}\right)$ and assuming that the density was constant. Two-way travel time was calculated by summing the slowness measured by the sonic log from the surface to the appropriate depth and multiplying by 2 . A zero-phase source waveform with a $10-$ to $80-\mathrm{Hz}$ bandwidth (which approximates the bandwidth of a Vibroseis source) was then convolved with the reflectivity log to produce the seismogram. The synthetic amplitudes are scaled by the maximum amplitude of the source waveform; thus the measured amplitudes correspond to the apparent reflection coefficients. Figure 12 shows the synthetic seismograms calculated for the MONT-1, MONT-2, XTLR, and Hi Vista wells. Also plotted in Figure 12 are the velocities and fracture densities as a function of two-way travel time, which allow direct comparison of the synthetic seismogram to the in situ data.

From the results in MONT-1 (Figure 12a) it is clear that although isolated fracture zones result in zones of distinctly lower velocity, the limited vertical extent of the zones compared to the seismic wavelength makes them difficult to detect. Although several fracture zones appear to produce low-amplitude reflections (e.g., at 245,300 , and $360 \mathrm{~m}$ ), the reflections would probably be difficult to resolve at depth in a seismic section. At MONT-2 (Figure $12 b$ ), however, some of the low-velocity zones are of sufficient vertical extent that distinct reflections are seen (e.g., at $100,140,240$, and $330 \mathrm{~m}$ ). In the XTLR well (Figure 12c), few distinct reflections are observed even though the well is quite fractured. The variations in velocity are too frequent to result in singular, distinguishable reflections. Interference between the energy reflected at various depths produces a zone of apparent reflectors, perhaps similar to that observed in sections of the Wind River Thrust on COCORP profiles [Smithson et al., 1978]. The average amplitude of the reflected energy in the XTLR synthetic is comparable to that of the synthetic from MONT-2. In the Hi Vista well (Figure 12d), several distinct reflections are seen that appear to correlate with changes in velocity due to fracturing. Also, a small reflection is observed at $200 \mathrm{~m}$, corresponding to the top of the lower fracture zone. Reflections are also observed at 250 and $300 \mathrm{~m}$ due to the velocity increase at $480 \mathrm{~m}$ and the abrupt decrease at the bottom of the well. The amplitudes of the reflections in the $\mathrm{Hi}$ Vista synthetic are comparable to the amplitudes from XTLR and MONT-2. However, in Hi Vista the source of the reflection is clearly related to the observed fracture density. At Hi Vista the synthetic trace is relatively quiet between the reflections, which suggests that the reflected energy would be easily distinguishable.

These synthetic seismograms demonstrate qualitatively that velocity changes associated with fracture zones similar to those observed in these wells can produce reflections for energy in a suitable frequency band. Although it is difficult to relate any of the 'events' observed in these synthetics directly to velocity anomalies, due to the problem of interference between adjacent reflections, it is significant that in several of the wells the velocity changes associated with fracture zones in crystalline rock appear to result in detectable reflections. If fracture zones like those found in these wells persist to great depth in the crust and if chemical alteration is as significant at great depth as it appears to be in the upper $1 \mathrm{~km}$, then the presence of fracture zones of sufficient thickness at midcrustal depths could produce significant reflections.

\section{Conclusions}

The presence of macroscopic fractures in situ lowers both $P$ and $S$ wave velocities and increases $V_{p} / V_{s}$ over a wide bandwidth. In situ macrofractures seem to affect velocity in a variety of ways: chemical alteration of the rock adjacent to macrofractures, increased microfracturing near the macrofractures, and the compliance of the macrofractures themselves all cause reductions in $P$ and $S$ wave velocity to some degree. The data suggest, however, that the effects of chemical and mechanical alteration may be very significant in lowering the elastic moduli and seismic velocity near macrofractures.

The magnitude of the velocity and its rate of change with depth in granitic rocks in the upper kilometer of the crust is largely controlled by the composition and microscopic properties of the rock. In general, the in situ velocity changes more rapidly with depth than laboratory data predict, which suggests that macrofractures are important in controlling the velocity- depth function.

Low-velocity zones produced by fracturing and its related effects appear to produce coherent reflections on synthetic seismograms, which suggests that crustal reflectors within crystalline rocks might result from fracture systems similar to those encountered in these wells, especially if chemical and mechanical alteration of the matrix is pervasive near macrofractures at depth.

\section{APPENDIX}

Sonic logs. We logged MONT-2, XTLR, and Hi Vista using a Simplec model CGY sonic velocity logging tool. The Simplec velocity tool consists of a downhole magnetostrictive pressure source and three receivers spaced $1.22,1.53$, and $2.14 \mathrm{~m}$ uphole from the source. An automatic 'picking' device at the surface determines the arrival time of a selected waveform at each receiver. The voltage threshold of the picking device is adjustable to compensate for changes in the received signal, and the waveforms are continually checked to ensure that the correct arrival is picked.

The sonic velocity is calculated by dividing the distance between two receivers by the travel time difference. The logs discussed here were obtained by differencing the arrival times to the receivers at 1.22 and $1.53 \mathrm{~m}$. Thus the sonic velocity was measured over a $30.5-\mathrm{cm}$ interval in the well about $1.22-1.53 \mathrm{~m}$ above the source depth. The frequency band of the received signal is $10-20 \mathrm{kHz}$.

Because of the nature of the picking device, changes in the amplitude of the received signal will produce small changes in the 
observed travel time. The largest this source of error can be is about $1 / 4$ period for each waveform; in general, however, when the amplitude varies enough to cause mispicking by about $1 / 8$ period, the picker will skip one or more cycles, and the resulting value of $\Delta t$ is removed before the analysis is carried out. Also, as the amplitudes of arrivals at the two receivers generally vary in the same manner, the arrival time errors will cancel when the interval travel time is calculated. Assuming that the signal has a fundamental frequency of $15 \mathrm{kHz}$ and that the largest error in arrival time is $1 / 8$ period, the largest error in $\Delta t$ should be $8 \mu \mathrm{s}$.

In order to study this effect, the amplitude of one of the two signals used to compute $\Delta t$ was varied while the threshold of the picking device was held constant. This resulted in a change in the calculated travel time of only $3 \mu \mathrm{s}$, or $\pm 3 \%$ of a $50-\mu$ s travel time. This results in an error of $\pm 3 \%$ in the calculated velocities. Thus, in practice, the errors in the travel time measurements introduced by variation in the amplitude of the arriving signal are less than half the maximum theoretical error. Therefore we believe the measurements of sonic velocity reported here are accurate to within $\pm 3 \%$ of the maximum velocity; lower velocities that result in longer travel times can be measured with correspondingly less error.

$P$ and $S$ wave sonic velocities in MONT-1 were obtained from a Birdwell three-dimensional velocity log with a 1.8 -m transmitter-receiver spacing. The logs we ran were recorded digitally by a Declab 11/03 minicomputer, and for direct comparison to the Birdwell logs in MONT-1, the figures displayed in the paper are a six-point running mean of the field data. Before the mean is taken, spurious $\Delta t$ values caused by cycle skipping are removed.

$S$ wave logs in the MONT-2 and Hi Vista wells were obtained with the $P$ wave logging tool by raising the voltage threshold of the picking device. As wave propagation in boreholes is extremely complicated, it is necessary to ensure that this method accurately measures $S$ wave velocity and not the velocity of some other mode. Several authors have discussed the characteristics of waveforms in cylindrical boreholes [see White and Zechman, 1968; Tsang and Rader, 1979; Cheng and Toksöz, 1981; Paillet, 1981]. Although such factors as borehole and tool radius and the acoustic properties of the surrounding rock and of the fluid in the borehole affect wave propagation, several features of the arrivals recorded by a sonic logging tool are common to all such measurements. In the case examined here (a water-filled borehole drilled through relatively fine-grained crystalline rock), both the shear and the compressional wave velocities of the rock are higher than the compressional velocity of the fluid. For this case both Cheng and Toksöz [1981] and Paillet [1981] found that the first arriving energy is a $P$ wave refracted along the borehole wall. The second arrival is a refracted $S$ wave. All of the other borehole modes, including the direct fluid wave and variously named normal modes (pseudo-Raleigh waves, Stonely waves, etc.), travel at velocities below that of the refracted shear wave. The experimental conditions in this study are similar to those described by Paillet and White [1982] as case 3. For this case the shear arrival is much larger than the compressional arrival and is easily separated from the pseudo-Rayleigh wave. This relationship is apparent in most of the waveforms recorded during our study. The method used should yield a reliable measurement of shear velocity as long as this relationship holds. Around fractures the relative amplitudes of the shear and compressional arrivals were more variable, and much greater care was required to ensure that the measurements were reliable. As the values of Poisson's ratio we obtained are reasonable for saturated granitic rock, we feel that the logs shown in Figures $\mathbf{3}$ and $\mathbf{5}$ do in fact accurately measure the in situ shear velocity.

VSP experiment. The source used for the vertical seismic profile at XTLR was a Rix Industries $\mathbf{4 0} \mathrm{cu}$.in. air gun operating at $2000 \mathrm{psi}$. The air gun was suspended in water in the center of a steel-sided cylindrical tank placed in a pit dug $25 \mathrm{~m}$ from the wellhead at XTLR. The pit was then filled with drilling mud to improve source coupling. The fundamental frequency of this source was about $75 \mathrm{~Hz}$; arrivals at depth had a bandwidth of about $25-250 \mathrm{~Hz}$.

The receiver used in the VSP experiment was a Mark Products L-10 geophone. The geophone was built into a sidewall clamped case which was placed at $30-\mathrm{m}$ intervals in the well to record the vertical component of motion. Interval velocities were calculated by differencing the travel time of successive shots over the $30-\mathrm{m}$ interval between geophone placements.

The shot time was recorded by a geophone placed inside the pit dug for the air gun. Tests were run to determine timing accuracy at various depths in the well. For a surface geophone the measured arrival time of successive shots was repeatable to within 0.2 ms. The worst case timing error was about $0.5 \mathrm{~ms}$. As the accuracy of the depth measurements was $0.5 \mathrm{~m}$, the calculated maximum error in interval velocity was about $8 \%$, or $\pm 0.4 \mathrm{~km} / \mathrm{s}$ for a velocity of $5 \mathrm{~km} / \mathrm{s}$.

Acknowledgments. The authors would like to thank the anonymous reviewers, whose helpful comments have substantially improved this manuscript. The field work was conducted with the assistance of Joe Svitek and Rich Liechti of the U.S. Geological Survey and was supported by the U.S Geological Survey while the principal author was a student at Stanford University.

\section{REFERENCES}

Birch, F., The velocity of compressional waves in rocks to $10 \mathrm{kbar}, 1, J$ Geophys. Res., 65, 1083-1102, 1960.

Birch, F., The velocity of compressional waves in rocks to $10 \mathrm{kbar}, 2, J$. Geophys. Res., 66, 2199-2228, 1961.

Bonner, B. P., Shear wave birefringence in dilating granite, Geophys. Res. Lett., 1, 217-220, 1974

Cheng, C. H., and M. N. Toksöz, Elastic wave propagation in a fluid-filled borehole and synthetic acoustic logs, Geophysics, 46, 1042-1053, 1981.

Jones, T. D., and A. Nur, Seismic velocity and anisotropy in mylonites and the reflectivity of deep crustal fault zones, Geology, 10, 260-263, 1982.

Keys, W. S., Preliminary interpretation of borehole geophysical dataWhiteshell Nuclear Research Establishment, Manitoba, Canada, Tech. Memo. 53, U.S. Geol. Surv., Denver, Colo., 1979.

Lockner, D. A., J. B. Walsh, and J. D. Byerlee, Changes in seismic velocity and attenuation during deformation of granite, J. Geophys. Res., 82 , 5374-5378, 1977.

Lynn, H. B., Migration and interpretation of deep crustal seismic reflection data, Ph.D. thesis, 158 pp., Stanford Univ., Stanford, Calif., 1979.

Mair, J. A., and A. G. Green, High resolution seismic reflection profiles reveal fracture zones within a "homogeneous" granite batholith, Nature. $294(5840), 439-442,1981$

Murphy, W. F., Effects of partial water saturation on attenuation in Massilon sandstone and Vycor porous glass, J. Acoust. Soc. Am., 7l(6), $1458-1468,1982$.

Nur, A., and G. Simmons, The effect of saturation on velocity in low porosity rocks, Earth Planet. Sci. Lett., 7, 183-193, 1969.

O'Connell, R. J., and B. Budiansky, Seismic velocities in dry and saturated cracked solids, J. Geophys. Res., 79, 5412-5426, 1974.

Paillet, F. L., Predicting the frequency content of acoustic waveforms obtainedin boreholes, Soc. Prof. Well Log Anal. Ann. Logging Symp. Trans. 22nd, 1, 1-29, 1981.

Paillet, F. L., and J. E. White, Acoustic modes of propagation in the borehole and their relationship to rock properties, Geophysics, 47(8), 1215-1228, 1982.

Peselnick, L., and R. Stewart, A sample assembly for velocity measure- 
ments of rocks at elevated temperatures and pressures, J. Geophys. Res., 80, 3765-3768, 1975.

Schilt, S., J. Oliver, L. Brown, S. Kaufman, D. Albaugh, J. Brewer, F. Cook, L. Jensen, P. Krumhansl, G. Long, and D. Steiner, The heterogeneity of the continental crust: Results from deep crustal seismic reflection profiling using Vibroseis technique, Rev. Geophys. Space Phys., 17, 354-368, 1979.

Seeburger, D., and M. D. Zoback, The distribution of natural fractures and joints at depth in crystalline rock, J. Geophys. Res., 87, 5517-5534, 1982.

Simmons, G., and A. Nur, Granites: Relation of properties in situ to laboratory measurements, Science, 162, 789-791, 1968.

Sjogren, B., A. Ofsthus, and J. Sandberg, Seismic classification of rock mass qualities, Geophys. Prospect., 27, 409-442, 1979.

Smithson, S. B., J. Brewer, S. Kaufman, J. Oliver, and C. Hunch, Nature of the Wind River Thrust, Wyoming, from COCORP deep-reflection data and from gravity data, Geology, 6, 648-652, 1978.

Spencer, J. W., Jr., Stress relaxations at low frequencies in fluid saturated rocks: Attenuation and modulus dispersion, J. Geophys. Res., $86,1803-1812,1981$.

Stesky, R. M., Compressional wave velocity of jointed rock: A laboratory simulation (abstact), Eos Trans. AGU, 60, 939, 1979.

Stierman, D. J., and R. L. Kovach, An in situ velocity study: The Stone Canyon well, J. Geophys. Res., 84, 672-678, 1979.

Talwani, P. D., B. K. Rastogi, and D. Stevenson, Induced seismicity and earthquake prediction studies in South Carolina, Tenth Tech. Rep., contract 14-08-0001-17670, U.S. Geol. Surv., Reston, Va., 1980.

Thomas, M. F., Granite landforms: A review of some recurrent problems of interpretation, in Progress in Geomorphology-Papers in Honor of D. L. Linton, Inst. Br. Geogr. Spec. Publ. 7, edited by E. H. Brown and R. S. Waters, pp. 13-38, Alden and Mowbray, London, 1974.

Thompson, T. F., San Jacinto tunnel, in Engineering Geology in Southern California, edited by R. Lund and R. Proctor, pp. 105-107, Association of Engineering Geologists, Los Angeles, Calif., 1966.

Todd, T., and G. Simmons, Effect of pore pressure on the velocity of compressional waves in low-porosity rocks, J. Geophys. Res., 77, 3731-3743, 1972.

Tsang, L., and D. Rader, Numerical evaluation of transient acoustic waveforms due to a point source in a fluid-filled borehole, Geophysics, 44, 1706-1719, 1979.

Wang, H. F., and G. Simmons, Microcracks in crystalline rock from 5.3 $\mathrm{km}$ depth in the Michigan Basin, J. Geophys. Res., 83, 5849-5856, 1978.

White, J. E., and R. E. Zechman, Computed response of an acoustic logging tool, Geophysics, 33, 302-310, 1968.

Zemanek, J., E. E. Glenn, Jr., L. J. Norton, and R. L. Caldwell, Formation evaluation by inspection with the borehole televiewer, Geophysics, 35, 254-269, 1970.

Zoback, M. D., and S. Hickman, In situ study of the physical mechanisms controlling induced seismicity at Monticello Reservoir, South Carolina, J. Geophys. Res., 87, 6959-6974, 1982.

Zoback, M. D., H. Tsukahara, and S. Hickman, Stress measurements at depth in the vicinity of the San Andreas fault: Implications for the magnitude of shear stress at depth, J. Geophys. Res., 85, 6157-6173, 1980.

(Received March 29, 1982;

revised September 23, 1982;

accepted November 15, 1982.) 